\title{
Finite Element-Based Micromechanical Modeling of the Influence of Phase Properties on the Elastic Response of Cementitious Mortars
}

\author{
Sumanta Das ${ }^{1, *}$, Amit Maroli $^{2}$, Narayanan Neithalath ${ }^{2}$ \\ ${ }^{1}$ Department of Civil and Environmental Engineering, University of Rhode Island, Kingston, RI, USA \\ ${ }^{2}$ School of Sustainable Engineering and the Built Environment, Arizona State University, Tempe, AZ, \\ USA. \\ *Corresponding Author (sumanta_das@uri.edu), Phone: 001-401-874-5637, Fax: 401-874-2786
}

\begin{abstract}
This study reports the influence of inclusion stiffness and its distribution on the stress distributions in the microstructural phases of different cementitious mortars using microstructure-guided finite element simulations. Randomly generated periodic microstructures with single/multiple inclusion sizes and random spatial distribution, subjected to periodic boundary conditions and a strain-controlled virtual testing regime are chosen for final analysis. Numerical simulations reveal: (i) the differences in locations/magnitudes of stress concentrations as a function of inclusion stiffness and size distribution, and (ii) the sometimes detrimental influence of matrix and interface stiffening/strengthening on the overall composite response, leading to material design strategies when non-conventional inclusions are used in cementitious systems for special properties. The constitutive behavior in the linear elastic regime is extracted based on the predicted dominant principal stresses and strains in the representative area element. Thus, in addition to the microstructural phase stresses, this methodology also provides predictions of the composite elastic modulus, which are observed to be more reliable than those obtained from analytical prediction models.
\end{abstract}

Keywords: Finite elements; Homogenization; Periodic boundary conditions; Microstructure; Constitutive behavior, Cementitious composite 


\section{INTRODUCTION}

The link between the material microstructure and relevant mechanical properties provides valuable information towards design and development of sustainable cementitious materials for several applications. In recent years, many novel cementitious composites have emerged, incorporating several types of inclusion materials for various special applications such as the use of lightweight aggregates (LWAs) for internal curing, reduction of dead load, thermal and acoustic insulation [1-4], microencapsulated phase change materials (PCM) for control of thermal cracking in pavements and bridge decks [5] and regulating internal environment in buildings [6,7], waste and recycled materials such as rubber for energy absorption [8], and denser/stiffer aggregates for radiation shielding $[9,10]$. Incorporation of such inclusions influences the individual stresses in the microstructural components and the stress distributions in the composite, thereby dictating the failure path/mechanism of the material. Hence a comprehensive understanding of the influence of inclusion types on the microstructural stress distribution is necessary to design such materials for desired mechanical performance.

In an attempt to elucidate the influence of stiffness of inclusions on the distribution of stresses in the different phases in cementitious systems, this study employs a microstructure-guided micromechanical modeling scheme using the finite element method. Traditionally, the influences of inclusion type and stiffness on the mechanical behavior (elastic modulus, strength) of cementitious systems are evaluated experimentally [11-13], or through analytical approaches such as Mori-Tanaka [14-16] and double inclusion $[17,18]$ models or iterative homogenization techniques $[19,20]$. Analytical homogenization techniques have been shown to provide good estimates of the effective property of cementitious systems [21,22]. However, these analytical and semi-analytical homogenization techniques do not have the capability to evaluate local stress concentrations around inclusions which influence the macroscopic behavior, especially for cementitious systems that exhibit heterogeneity at a microscopic scale. Thus, microstructure-guided numerical modeling is a favored approach under such considerations. Microstructure-guided simulations have been performed on cementitious materials using randomly generated microstructures [23-28] or image-based microstructures [29,30]. A few recent studies have evaluated stress localization in the lightweight aggregate-matrix interface using an analytical approach [31] or through a macroscopic numerical simulation of a compression test [32], thus helping to understand the effect of soft inclusions on mechanical properties. In this paper, 2D periodic microstructures for mortars containing spherical quartz (stiff) or lightweight aggregate (soft) inclusions, 
including the interfacial transition zone (ITZ) around inclusions, are generated virtually and the representative element areas (REA) thus obtained are numerically analyzed using finite elements by invoking periodic boundary conditions [33-35]. The fundamental differences in stress distributions in the microstructure as a function of the inclusion type, and the relative efficiency of matrix and interface stiffening are clearly brought out. In addition, the constitutive relationships in the linear elastic regime (considering in-service performance of structures) are also evaluated for both the material systems considered. Such comprehensive numerical evaluations of fundamental differences in local micro-stress distributions imparted by differences in inclusion type, and its resultant influence on the macroscale mechanical response are rather uncommon.

\section{MICROSTRUCTURAL MODELING}

\subsection{Phase Elastic Properties}

The constitutive relationships for all the components: cement paste, hard (quartz aggregates) and soft (lightweight aggregate - LWA) inclusions, and the paste-inclusion interfaces are considered in their respective linear elastic regimes only. The default elastic properties of the components, extracted from available literature [14,36-41], are presented in Table 1. However, for parametric studies discussed later in the paper, a range of values are considered, which are indicated in the respective sections. The interfacial transition zone between cement paste and hard, non-porous aggregates such as quartz are known to be more porous than the bulk paste. In the case of saturated LWA inclusions in the mixture, they provide additional water and enables an increased degree of hydration, which densifies the microstructure. The densification is typically observed at the cement-aggregate interface [42], thereby stiffening the interface. This effect is accounted for in the parameters used for simulation.

Table 1: Elastic properties of the components of the mortar for FE simulations

\begin{tabular}{|c|c|c|c|c|c|}
\hline Elastic property & $\begin{array}{c}\text { Hardened } \\
\text { cement } \\
\text { paste }\end{array}$ & $\begin{array}{c}\text { Quartz } \\
\text { inclusion }\end{array}$ & $\begin{array}{c}\text { Quartz- } \\
\text { cement } \\
\text { paste } \\
\text { interface }\end{array}$ & $\begin{array}{c}\text { LWA } \\
\text { inclusion }\end{array}$ & $\begin{array}{c}\text { LWA-cement } \\
\text { paste } \\
\text { Interface }\end{array}$ \\
\hline Young's Modulus, E (GPa) & 20 & 70 & 15 & 16 & 30 \\
\hline Poisson's Ratio, v (--) & 0.22 & 0.17 & 0.22 & 0.20 & 0.20 \\
\hline
\end{tabular}

\subsection{Finite Element Models: Examining the Influence of Boundary Conditions and Phase Distribution}

Two-dimensional plane strain microstructural finite element models are employed here in order to examine the influence of inclusion and matrix properties on the bulk elastic behavior of the composite 
system. A sufficiently large $(4.15 \mathrm{~mm} \times 4.15 \mathrm{~mm})$ representative element area (REA) has been considered for the analysis. The spatial distribution of inclusions and the chosen boundary conditions play an important role in any numerical stress analysis procedure [33,34]. The choice of boundary conditions as well as the spatial distribution of inclusions need to be thoroughly investigated since the boundary conditions are applied on the REA and the averaged response of REA is used as an indicator of the influence of the microstructural phases. Hence, this section investigates the effect of different boundary conditions and distribution of inclusions (in the REA) on the stress distribution in order to establish the appropriate parameters for detailed studies. Under uniaxial conditions, the value of higher eigenstress is significantly higher as compared to the other two. Here, the values of $\sigma_{11}$ and $\sigma_{33}$ are always lower than $\sigma_{22}$. Hence, In this paper, dominant principal stress ( $\sigma_{22}$ in this case) is taken as the microstructural stress measure [32].

\subsubsection{Regular arrays and essential boundary conditions}

In many numerical stress analysis simulations of matrix-particulate inclusion composites (such as mortar or concrete), the actual material is simplified into a model that considers either a single spherical inclusion and the matrix surrounding it $[43,44]$ or a uniform array of spherical (or circular, in 2D) particles in a continuous matrix $[45,46]$. The single inclusion case is generally applicable for low concentrations of particles (dilute limit). Figure 1(a) shows a quarter model containing a uniform array of particles with essential (displacement) boundary conditions [47] applied at the left and bottom edges, considering symmetry. The REA contains circular quartz particles (aggregates) arranged in a square lattice within a cement paste matrix, and contains $50 \%$ inclusions. The interfacial zone around the aggregates are also accounted for. The top face of the geometry is subjected to uniform compressive loading parallel to the $\mathrm{Y}$-axis. The analysis is performed using ABAQUS ${ }^{\mathrm{TM}}$. Figure 1 (b) shows the stress distribution in the REA for an applied external stress of $40 \mathrm{MPa}$. While this configuration results in concentration of stresses at the top face due to direct application of load, the stress concentrations at the left and bottom edges are avoided due to the effective clearance between the inclusions and the boundaries. Moreover, when considering a heterogeneous material such as cement mortar, such a perfectly ordered regular lattice structure of inclusions fails to capture the randomness of particle distribution and the resultant stress distributions. This limits the application of such models for the case of random particulate composites even when the assumption of homogeneity can be applied to the global microstructure. 


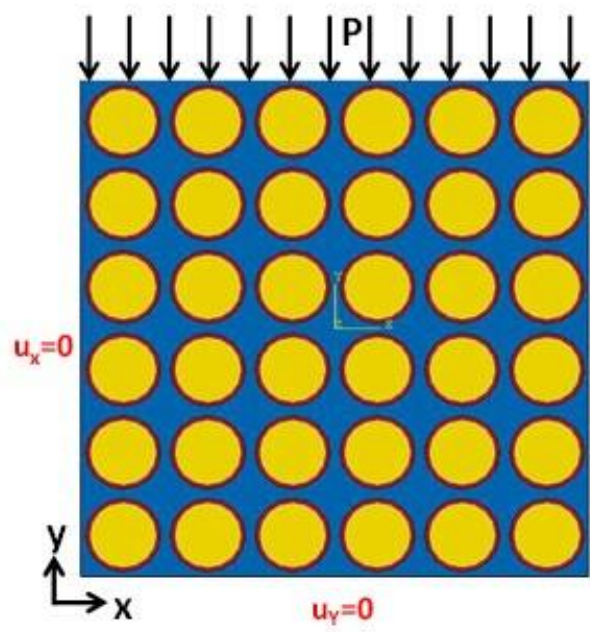

(a)

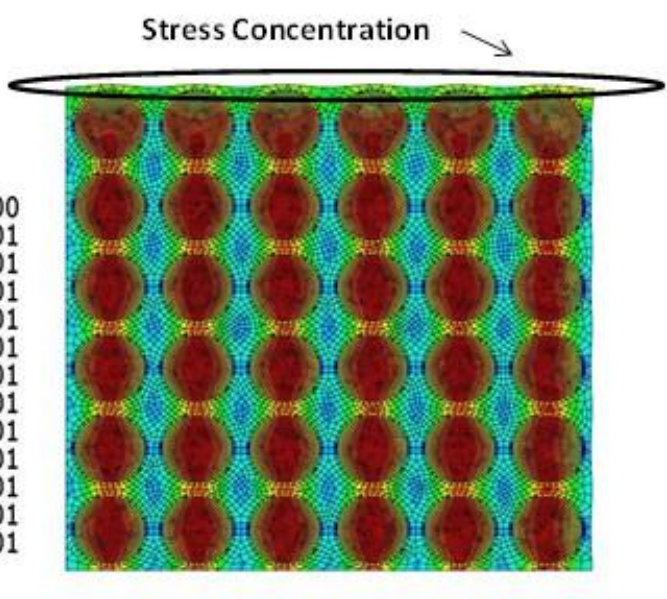

(b)

Figure 1: Model-I: (a) FE model showing the essential boundary conditions at the edges and applied compressive loading for a regular lattice of inclusions containing interfacial zones around them. The model contains $50 \%$ of inclusions by volume (or area); (b) effect of regular inclusion distribution on the stress distribution under the boundary conditions shown and an external stress of $40 \mathrm{MPa}$. The average REA stress is $36.97 \mathrm{MPa}$ (compression, shown by the negative sign of $\sigma_{22}$ ).

\subsubsection{Improvements through the use of periodic microstructure and periodic boundary conditions}

The limitations discussed above necessitate improvements in the model formulation with respect to the geometrical features of the microstructure where the spatial randomness in particle distribution is considered. Figure 2(a) shows such an improved model. The virtual random periodic microstructure is generated using a microstructural stochastic packing algorithm [48-50]. This algorithm requires the particle size distribution (PSD) and the volume fraction of particles as inputs and it packs the circular inclusions with an interface layer of predefined thickness around them inside a REA of $4.15 \mathrm{~mm} \times 4.15$ $\mathrm{mm}$. Generation of particles and their packing in the REA is allowed if the minimum distance between the centroids of neighboring particles is always greater than the sum of their radii., i.e.,, the interfacial zones are allowed to overlap in this packing scheme. Generation and random spatial placement of inclusions goes on simultaneously until the target volume fraction of inclusions is reached. The algorithm is described in detail in [49]. Note that Figure 2(a) shows only single size inclusions even though multiple sizes, based on inclusion PSD can be incorporated, which is implemented in a forthcoming section. After the generation of the microstructure, the REA is meshed using a Python script [51] through ABAQUS ${ }^{T M}$ and thus an orphan mesh file is obtained. Similar boundary conditions and loading as in the previous case (Figure 1) are applied. Figure 2(b) shows the dominant principal stress ( 
$\sigma_{22}$ ) distribution in the REA. The stresses in the inclusions are similar to that in the case of regular arrangement (Figure 1(b) - the color coding is different from that in Figure 1(a) because of extremely high stress concentrations in this case). However the magnitude of the concentrated stresses are much higher in the regions where the inclusions intersect the edges of the REA. This artifact created by the intersection of particle with the REA boundaries are addressed as described below.

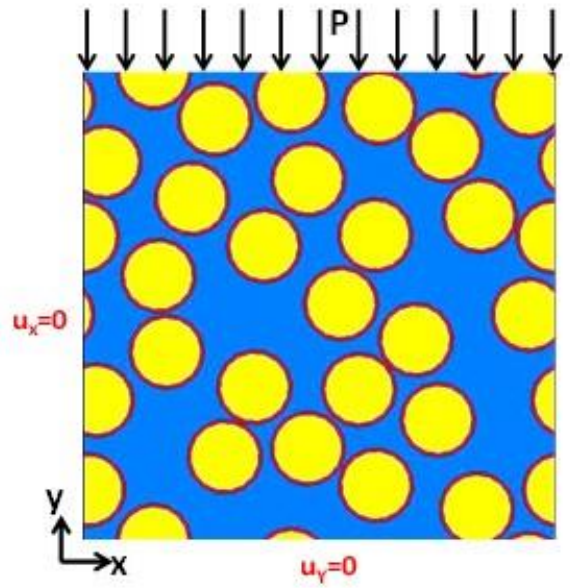

(a)

\section{S, S22}

(Avg: 75\%)

$-7.282 e+00$

$-1.483 e+01$

$-2.238 \mathrm{e}+01$

$-2.992 e+01$

$-3.747 e+01$

$-4.502 e+01$

$-5.256 e+01$

$-6.011 e+01$

$-6.766 e+01$

$-7.520 \mathrm{e}+01$

$-8.275 e+01$

$9.030 e+01$

$-9.784 \mathrm{e}+01$

Figure 2: Model-II: (a) FE model showing the essential boundary conditions at the edges and applied compressive loading for a randomized spatial distribution of inclusions containing interfacial zones around them. The model contains $50 \%$ of inclusions by volume (or area); (b) effect of random spatial distribution of inclusions on the stress distribution under the boundary conditions shown and an external stress of $40 \mathrm{MPa}$. The average REA stress is $37.2 \mathrm{MPa}$

In order to eliminate the boundary effects, periodic boundary conditions [33-35] are employed in the 2D REA as shown in Figure 3. Figure 3(a) shows schematic periodic arrays of repetitive unit cells and Figure $3(b)$ shows the periodic boundary conditions applied on one of such schematic representative elements for illustration. Periodic boundary condition ensures two continuity criteria at the boundaries of neighboring unit cells in order to ensure assembly of individual unit cells as a physical continuous body [52]: (i) displacement continuity, i.e., neighboring unit cells cannot be separated or they cannot penetrate each other; and (ii) traction continuity at the boundary of neighboring unit cells. The displacement field in any periodic microstructure is given as:

$$
v_{i}\left(x_{1}, x_{2}\right)=\varepsilon_{i j}^{0} x_{j}+v_{i}^{*}\left(x_{1}, x_{2}\right)
$$


Here, $\varepsilon_{i j}^{0}$ is the applied strain tensor, and $v_{i}^{*}$ is a periodic function representing the modification of linear displacement field due to the heterogeneous microstructure. For, the unit cell shown in Figure 3(b), the displacements on a pair of parallel opposite boundary edges are given as:

$$
\begin{aligned}
& v_{i}^{s+}=\varepsilon_{i j}^{0} x_{j}^{s+}+v_{i}^{*} \\
& v_{i}^{s-}=\varepsilon_{i j}^{0} x_{j}^{s-}+v_{i}^{*}
\end{aligned}
$$

Here, $s^{+}$and $s^{-}$are $s^{\text {th }}$ pair of two opposite parallel boundary surfaces of the unit cell as shown in Figure $3(b)$. The periodic function $v^{*}$ is the same at both the parallel opposite edges due to periodicity. The difference between the displacement fields of the two opposite parallel boundary edges is given as:

$$
v_{i}^{s+}-v_{i}^{s-}=\varepsilon_{i j}^{0}\left(x_{j}^{s+}-x_{j}^{s-}\right)=\varepsilon_{i j}^{0} \Delta x_{j}^{s}
$$

For a pair of opposite parallel boundary edges, $\Delta x_{j}^{s}$ is constant for a specified $\varepsilon_{i j}^{0}$. Such equations are applied as nodal displacement constraints in the finite element (FE) microstructural analysis.

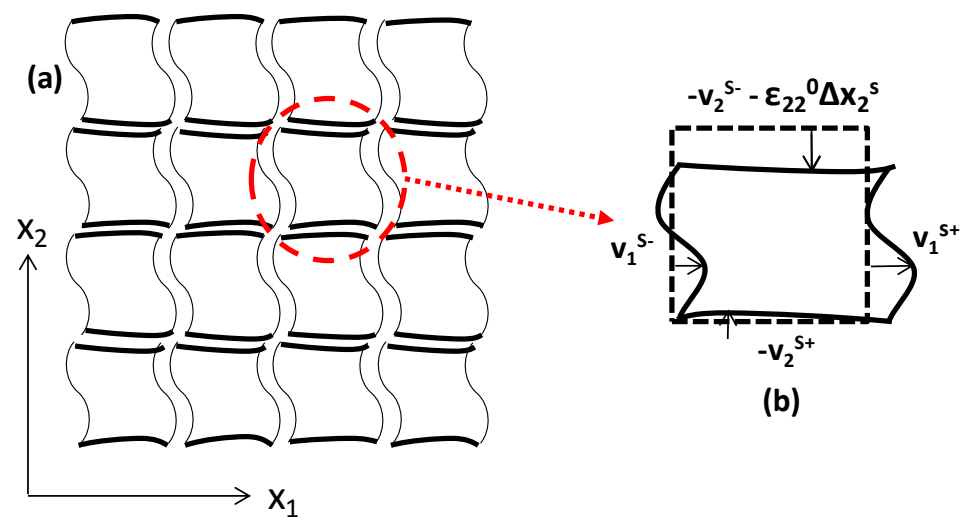

Figure 3: Schematic representative element area (REA) under applied strain $\left(\varepsilon_{22}^{0}\right)$ with periodic boundary conditions

Periodic boundary condition is implemented on the REA as nodal displacement constraints through a Python language program appended to the previously obtained (for Model-II, Figure 2) orphan mesh file containing the periodic microstructure information. A specific strain is applied on the REA and the analysis is implemented through $A B A Q U S^{T M}$ solver. Thus this approach simulates a strain- (or displacement) controlled test scenario. To efficiently handle post-processing of the simulated individual element stresses, a homogenization module is developed to obtain effective area-averaged REA 
stresses/strains [53] and the effective individual phase stresses/strains. Figure 4(a) shows the generated periodic microstructure and Figure 4(b) shows the stress distribution obtained after analysis (Model-III) under the application of an imposed strain of $0.12 \%$ (which is well within the linear elastic range of cementitious systems). This value of strain provided an average REA stress of $36.13 \mathrm{MPa}$, which is very similar to the average REA stresses obtained for Models I and II when an external stress of $40 \mathrm{MPa}$ was applied. Application of periodic boundary conditions on an REA under a strain-controlled regime eliminates all the boundary effects encountered in Models I and II. Hence this model (Model III) is used for further analysis in this paper. Free quad-dominated 4-noded bilinear plane strain quadrilateral elements (CPE4R element implemented in ABAQUS ${ }^{\mathrm{TM}}$ ) are used in the FE models. A mesh convergence study was conducted so as to establish the mesh size for FE analysis. For an REA of $4.15 \mathrm{~mm} \times 4.15 \mathrm{~mm}$, a seed size of $0.0175 \mathrm{~mm}$ was found to yield converging responses for all sizes and volume fractions of inclusions. The finest mesh (68879 nodes and 68771 elements) that yielded a converged solution is shown in Figure 4(b) and is used in further simulations (Section 3). A seed size of $5 \mu \mathrm{m}$ is used at the aggregate-paste interface. The analysis scheme presented here does not consider the separation effects of phases (debonding) under stress. Application of low strains (or stresses) ensures adherence to the principles of linear elasticity and that the interface debonding effects are not dominant.

A flowchart that depicts the modeling and analysis sequence employed in this study is shown schematically in Figure 5. Area-averaged dominant principal stresses and strains in the REA, computed using the FE analysis, are calculated at different externally applied uniaxial displacements in order to obtain the effective composite Young's modulus. 


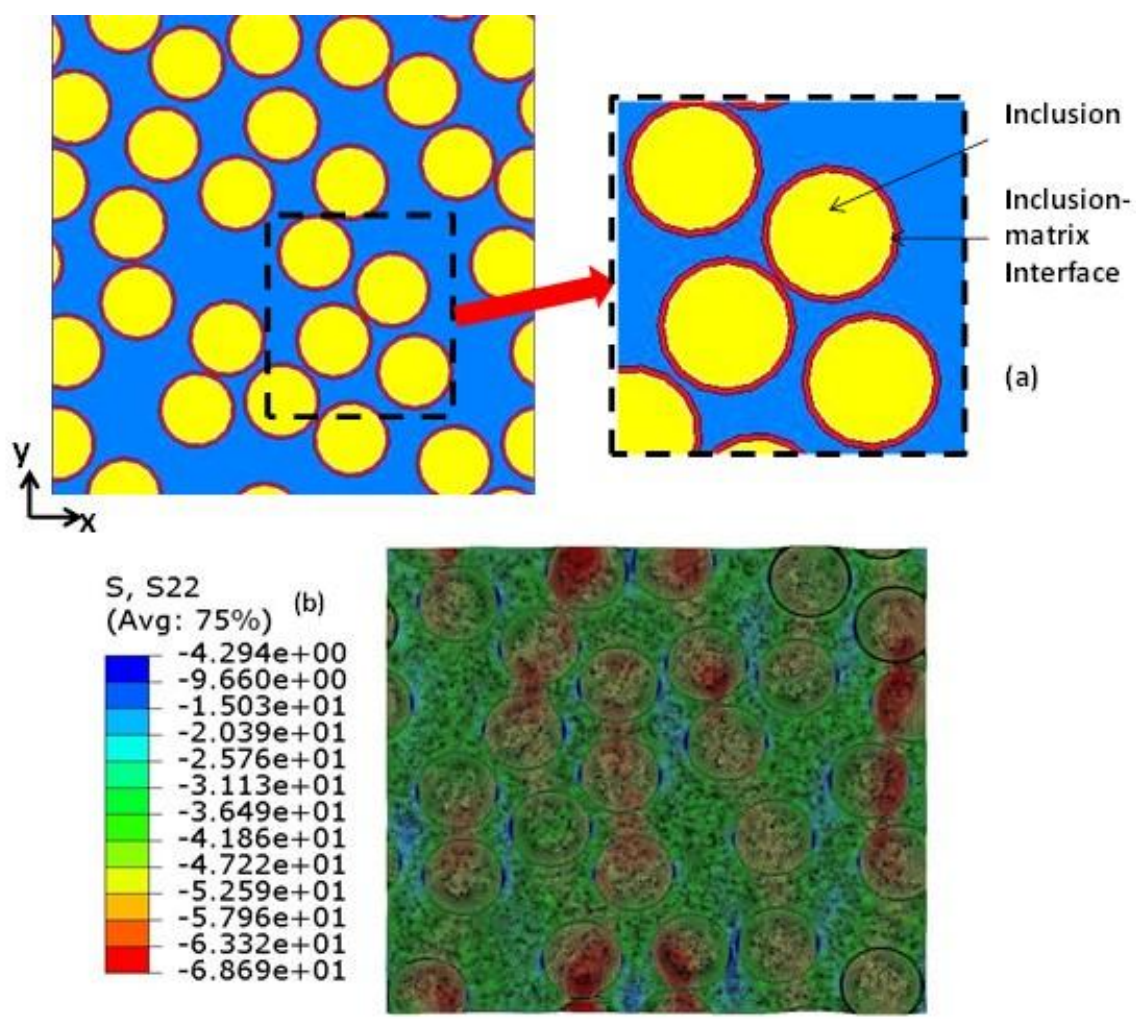

Figure 4: Model-III: (a) FE model showing the inclusions with the interfacial zones around them. The model contains $50 \%$ of inclusions by volume (or area); (b) effect of random distribution and periodic boundary conditions on the stress distribution under an imposed strain of $0.12 \%$. The average REA stress is $36.13 \mathrm{MPa}$. 


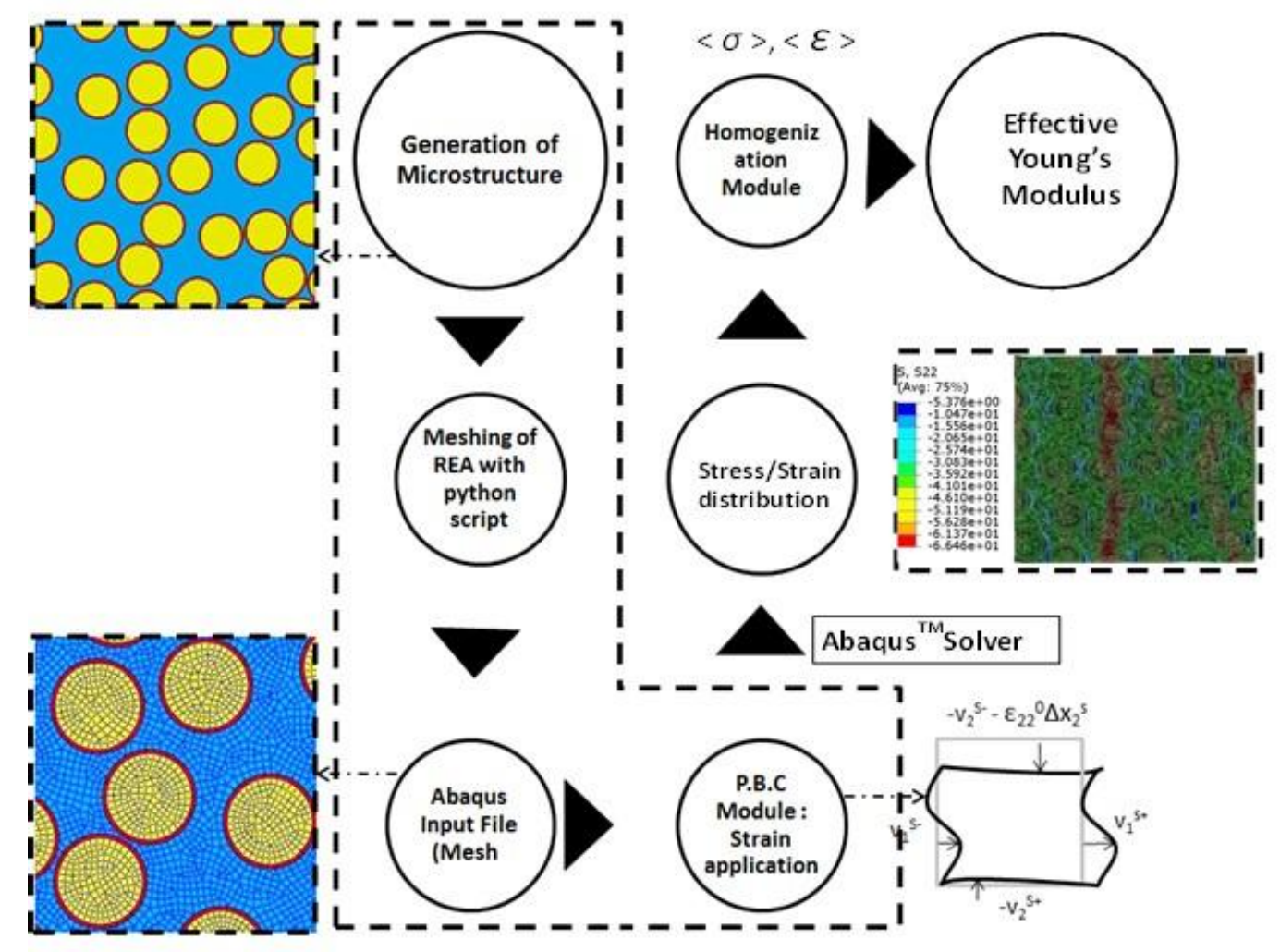

Figure 5: The sequence followed in the numerical analysis process including microstructural generation, meshing, application of periodic boundary conditions, homogenization, and determination of average REA stresses and effective E. (P.B.C denotes periodic boundary conditions).

\section{RESULTS FROM NUMERICAL SIMULATIONS AND DISCUSSIONS}

Based on the discussions in the previous section, simulations are carried out on periodic virtual microstructures on which periodic boundary conditions are imposed (Model III). This section evaluates the sensitivity of the averaged (within a given phase or the REA) linear elastic stress responses as a function of varying material and geometric parameters of the microstructure, and brings out the fundamental differences in elastic response between systems containing hard (quartz) or soft (lightweight aggregates) inclusion particles. This study is limited to two-dimensional numerical simulations since it has been shown to provide similar trends in stress distributions and yields acceptable predictions of macroscopic properties [28] at significantly lower computational costs as compared to $3 \mathrm{D}$ analysis. This is especially significant when the inclusion volume fraction is $50 \%$, along with the consideration of interfacial transition zones, as is carried out in this study. Hence, 2D simulations are adopted here as a tradeoff between prediction efficiency and computational demand. However, to demonstrate that the 2D and 3D simulations yield comparable results, the elastic modulus 
is predicted in a 3D volume with an inclusion (quartz) fraction of $30 \%$ to maintain the computational expense within reasonable limits.

Figure 6(a) shows the generated unit cell for $30 \%$ area fraction of quartz inclusions (size of inclusions is considered to be identical $(600 \mu \mathrm{m}))$ and Figure $6(\mathrm{~b})$ shows the stress distribution in the unit cell for applied strain of $0.12 \%$. For an inclusion Young's modulus of $70 \mathrm{GPa}, 2 \mathrm{D}$ simulation predicts an effective Young's modulus of $25.3 \mathrm{GPa}$. Figure $7(\mathrm{a})$ shows the 3D RVE containing $30 \%$ volume fraction of quartz incisions. The particle size distribution of sand was obtained using a Static Light Scattering (SLS) Particle Size Analyzer [54]. Figure 7(b) exhibits the stress distribution in the RVE. In the case of 3D analysis, the stresses are slightly lower as compared to the 2D simulation results as can be seen from Figures $6(\mathrm{~b})$ and 7(b). Stresses are concentrated inside the stiffer quartz inclusions and the stress concentrations are higher when the inclusions are very close to each other in both the simulations. Figure 7 (c) shows the predicted effective composite Young's modulus as a function of the Young's modulus of the inclusions when $2 \mathrm{D}$ or $3 \mathrm{D}$ simulations are implemented. The similarity in the $2 \mathrm{D}$ and $3 \mathrm{D}$ results verify the fact that 2D simulations can be used to reliably simulate the macroscopic properties of the system under consideration.

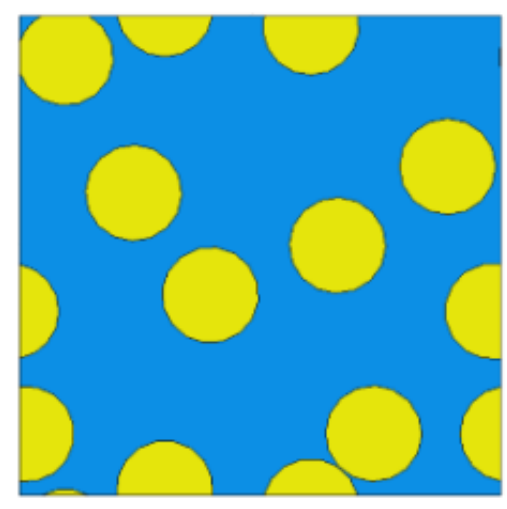
(a)

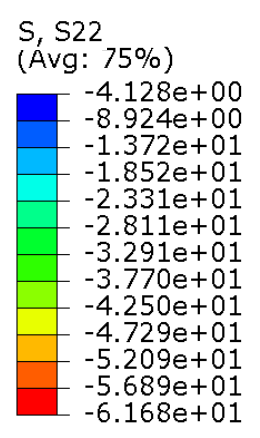

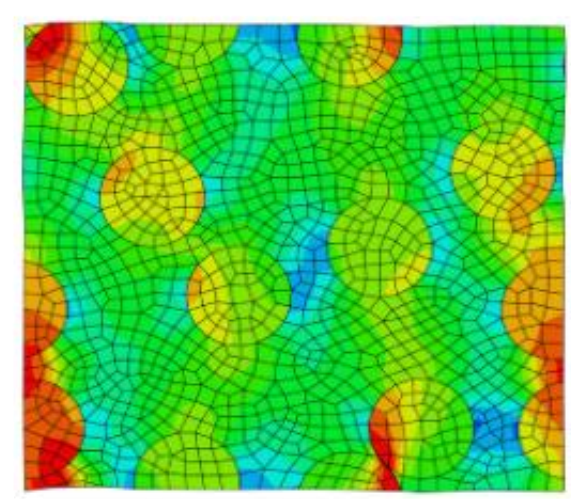

(b)

Figure 6: (a) 2D FE model showing the quartz inclusions (30\%) and matrix; (b) stress distributions for an applied strain of $0.12 \%$. 


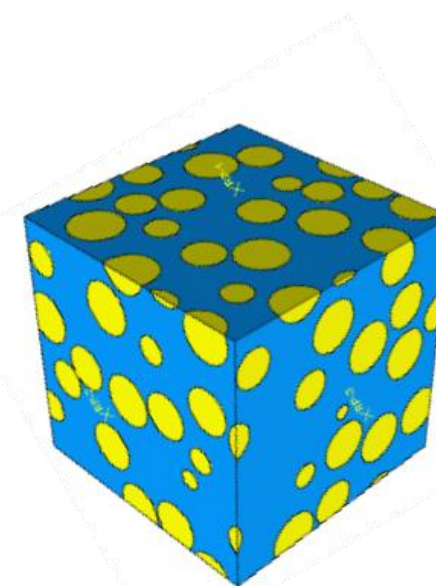

(a)
$\mathrm{S}, \mathrm{S} 22$

(Avg: $75 \%$ )

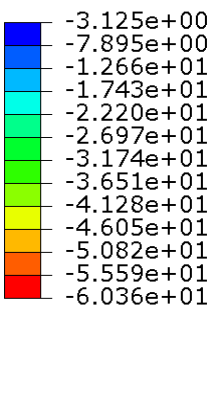

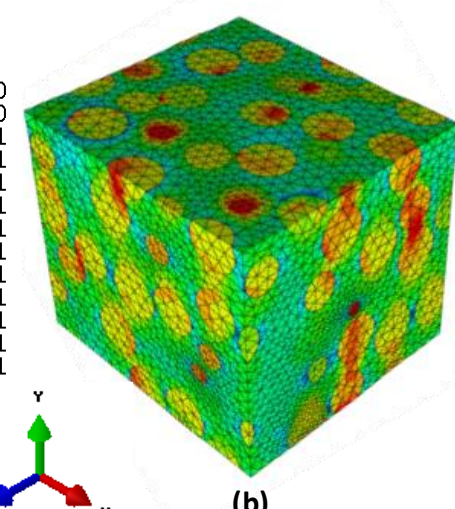

(b)

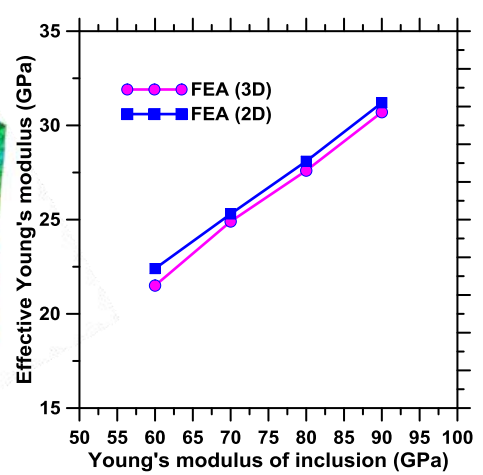

(c)

Figure 7: (a) 3D FE model showing the quartz inclusions (30\%) and matrix; (b) stress distributions for an applied strain of $0.12 \%$, and (c) comparison of effective elastic modulus from $2 \mathrm{D}$ and 3D simulations

In this study, the size of inclusions is considered to be identical $(600 \mu \mathrm{m})$ for both the quartz and lightweight aggregate systems, for simplicity. The default volume fraction of inclusions for the remainder of this study is $50 \%$. However, the modeling technique and discussions presented herein are not restricted to such simplified systems and can tackle any realistic inclusion sizes and volume fractions. The effect of multiple inclusion sizes on the effective stresses is also demonstrated later in this paper. The thickness of inclusion-matrix interface has been kept constant at $30 \mu \mathrm{m}$ for the simulations $[36,40,41]$. The default material properties of different components are reported in Table 1.

\subsection{Influence of Material Properties}

In this section, the sensitivity of effective REA and individual phase stresses in quartz and LWA mortar systems to variations in material properties are evaluated.

\subsubsection{Influence of inclusion stiffness and prediction of composite $E$}

Figures $8(a)$ and (b) show the dominant principal stress $\left(\sigma_{22}\right)$ distribution considering the material properties shown in Table 1 for both the quartz and LWA mortar systems respectively, when a strain of $0.12 \%$ is applied to the REA. The LWA inclusions exhibit significantly higher deformation as compared to the quartz inclusions as can be seen from these figures, which is expected. While the quartz particles are highly stressed in the quartz mortar system, in the LWA mortar, it is the ITZ that bears the highest stress. This is expected considering the significantly higher stiffness of quartz particles as compared to that of LWA as shown in Table 1. Another distinct observation from Figure 8 is that the magnitude of stress inside the quartz particles increases when the particles are very close to each other, attributable to the 
significant stiffness mismatch between the inclusions and the matrix. On the contrary, LWA mortar does not exhibit an increase in stress inside LWA. Instead, the stress concentration in the ITZ is higher if the neighboring particles are close to each other. Thus, the relative stiffness of the inclusions with respect to the matrix results in distinctively different stress distributions, and thus differing propensities of failure in the microstructure. Note that the magnitude of the maximum dominant principal stresses $\left(\sigma_{22}\right)$, which occur in the inclusions when the inclusion is stiffer and the inclusion-paste stiffness mismatch is higher, and in the ITZ when inclusion-paste stiffness mismatch is lower, are rather comparable. The quantified averaged REA stress and the stresses in the other microstructural phases are plotted in Figure 9 as a function of the inclusion stiffness.

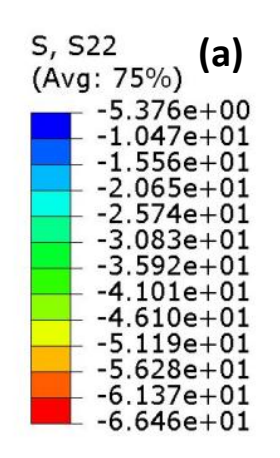

$$
\begin{array}{r}
\text { S, S22 (b) } \\
\text { (Avg: } 75 \%) \text { (b) } \\
-6.908 \mathrm{e}+00 \\
-1.111 \mathrm{e}+01 \\
-1.531 \mathrm{e}+01 \\
-1.950 \mathrm{e}+01 \\
-2.370 \mathrm{e}+01 \\
-2.790 \mathrm{e}+01 \\
-3.210 \mathrm{e}+01 \\
-3.630 \mathrm{e}+01 \\
-4.050 \mathrm{e}+01 \\
-4.470 \mathrm{e}+01 \\
-4.890 \mathrm{e}+01 \\
-5.310 \mathrm{e}+01 \\
-5.729 \mathrm{e}+01
\end{array}
$$
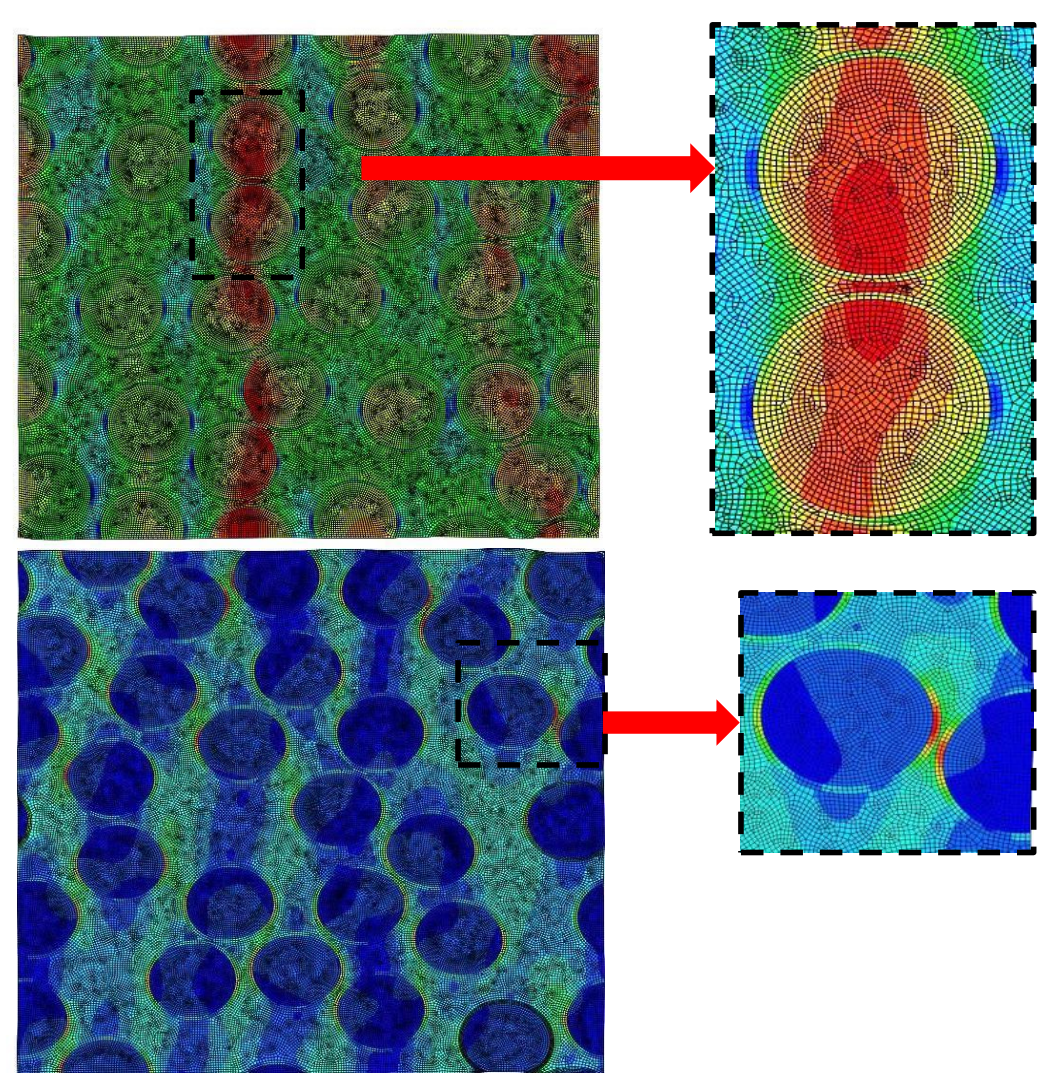

Figure 8: Dominant principal stress $\left(\sigma_{22}\right)(\mathrm{MPa}$ ) distributions in: (a) quartz mortar system and (b) lightweight aggregate mortar system. Magnified representation of stress distributions in both mortar systems containing the zones around the inclusions are shown for clarity. The REA is subjected to a strain of $0.12 \%$. 
Figure 9(a) shows the area-averaged dominant principal stresses in the REA as well as those in the individual microstructural phases for a mortar system containing quartz particles as a function of the Young's modulus of quartz (in the range of 50 to $100 \mathrm{GPa}$ ). With increasing $\mathrm{E}$ of quartz (at the same inclusion volume fraction, and leaving the $E$ of the paste and the interface unchanged), the average stresses in all the phases in the microstructure increase linearly. The quartz inclusions experience the highest average stress amongst all the phases because of the significantly higher E values compared to the paste or the ITZ, in line with Figure 8(a). The ITZ and the paste matrix components show similar averaged stresses, attributable to the fact that the stiffness difference between these phases is negligible when compared to the difference in stiffness between quartz and these phases. Figure 9(b) shows the averaged REA and other component stresses in the LWA mortar system for varying stiffness of LWA inclusions (between 6 and 21 GPa [38]). Here, the highest stress is observed in the ITZ as shown in Figure $8(b)$ because of the fact that its stiffness is the highest among all the phases in this microstructure. While the average stress increases in all the phases when stiffer LWA is used, the rate of increase in stress is higher in the LWA inclusions compared to the other phases or the REA. The average stress in the cement paste matrix and ITZ of the LWA mortar system linearly increases with LWA stiffness whereas the stress increase in the LWA inclusions is found to be nonlinear, primarily attributed to the deformational effects of the LWA and the consideration of perfect bonding between the phases in the model. The rate of stress increase in the LWA and the paste decreases with increasing LWA stiffness and the stresses in these phases are almost equal when the LWA and the paste stiffness are similar, as expected. Figures 9(a) and (b) also show that the averaged stresses in all the components are lower in the LWA system as compared to those in quartz mortar system. This can be attributed to the stresses concentrated over large areas in quartz particles that increases the average inclusion stresses as well as the other phase stresses in quartz mortar system due to assumption of perfect bonding between phases. On the contrary, LWA system shows lower stresses due to lower stiffness of LWA inclusions as well as lower effective stiffness of REA. Furthermore, several important, microstructure-based designrelevant considerations are obtained through these simulations, which are summarized below:

(i) Although significant stress concentrations are observed inside stiff particles in the quartz mortar, the interfaces between the paste and the inclusions are more critical since ITZ is the weakest component in this system and the stiff inclusions can sustain significantly higher load without failure. The average stress in ITZ increases by about $16 \%$ and the average REA stresses by about $20 \%$ when the $E$ of the stiff inclusion is doubled, denoting that there is no significant advantage in terms of propensity to fail (strength) even if a very stiff (and thus generally strong) inclusion is used, unless 
the paste (and interface) properties are concurrently altered. However, at low strains, the beneficial effects of a higher composite stiffness also cannot be discounted;

(ii) Even though the inclusions in the LWA mortar exhibit the lowest stress among all the components under applied external strains, the softer and weaker (compared to the cement paste matrix and ITZ) LWA inclusions are critical towards failure of LWA mortar system;

(iii) Tripling the stiffness of LWA inclusions (within limits without compromising various benefits of LWAs such as low density and thermal performance) results in more than doubling of the stress in the LWA inclusions. While stiffening of LWA inclusions increases the stress inside LWA inclusions, the strength of the inclusions also likely increases concurrently. Hence a suitable combination of stiffening and strengthening of LWA inclusions can be selected for optimal mechanical performance;

(iv) Increase in stiffness of LWA inclusions is also associated with increase in stress in the ITZ and matrix. Hence, the results indicate that the ITZ and matrix also needs to be strengthened if the LWA stiffness (and strength) is to be increased. These results exhibit that the fundamental materialdesign approach, which is based on traditional stiff inclusion incorporation, needs to be altered when softer inclusions are incorporated in cementitious systems.

The modeling approach and the results described here indicate the probable failure modes and provide valuable information on the mechanical performance and design of particulate composite materials such as mortars and concrete, especially when new inclusion materials are used for specific performance features or to address sustainability issues (e.g., the use of different types of soft inclusions such as LWAs for internal curing [2,55], fly ash-based aggregates [56,57], microencapsulated phase change materials for thermal cracking control [5], and waste and recycled materials such as rubber for energy absorption [8]). It is reiterated that the models consider perfect bonding between the particles and the matrix; a case not completely realistic, but helps provide comparisons of material response.

Figure 9(c) shows the constitutive response of the quartz and LWA mortars containing $50 \%$ of inclusions by volume, extracted from numerical simulations. The dominant principal stresses $\left(\sigma_{22}\right)$ and principal strains $\left(\varepsilon_{22}\right)$ in the linear elastic range of these systems are used. Thus the approach presented here can be used to determine the composite elastic moduli of systems containing multiple inclusion types. In addition to the $E$ value, as described earlier, this methodology also provides estimates of the microstresses in the different phases under imposed strains (in the linear elastic regime) and facilitates the development of constitutive relationships for composite materials, which otherwise would be experimentally tedious. Comparison of Young's modulus values obtained from numerical simulation 
(FEA) to those calculated using analytical/semi-analytical approaches as well as experimental validation of the adopted numerical technique is detailed in a later section of this paper.
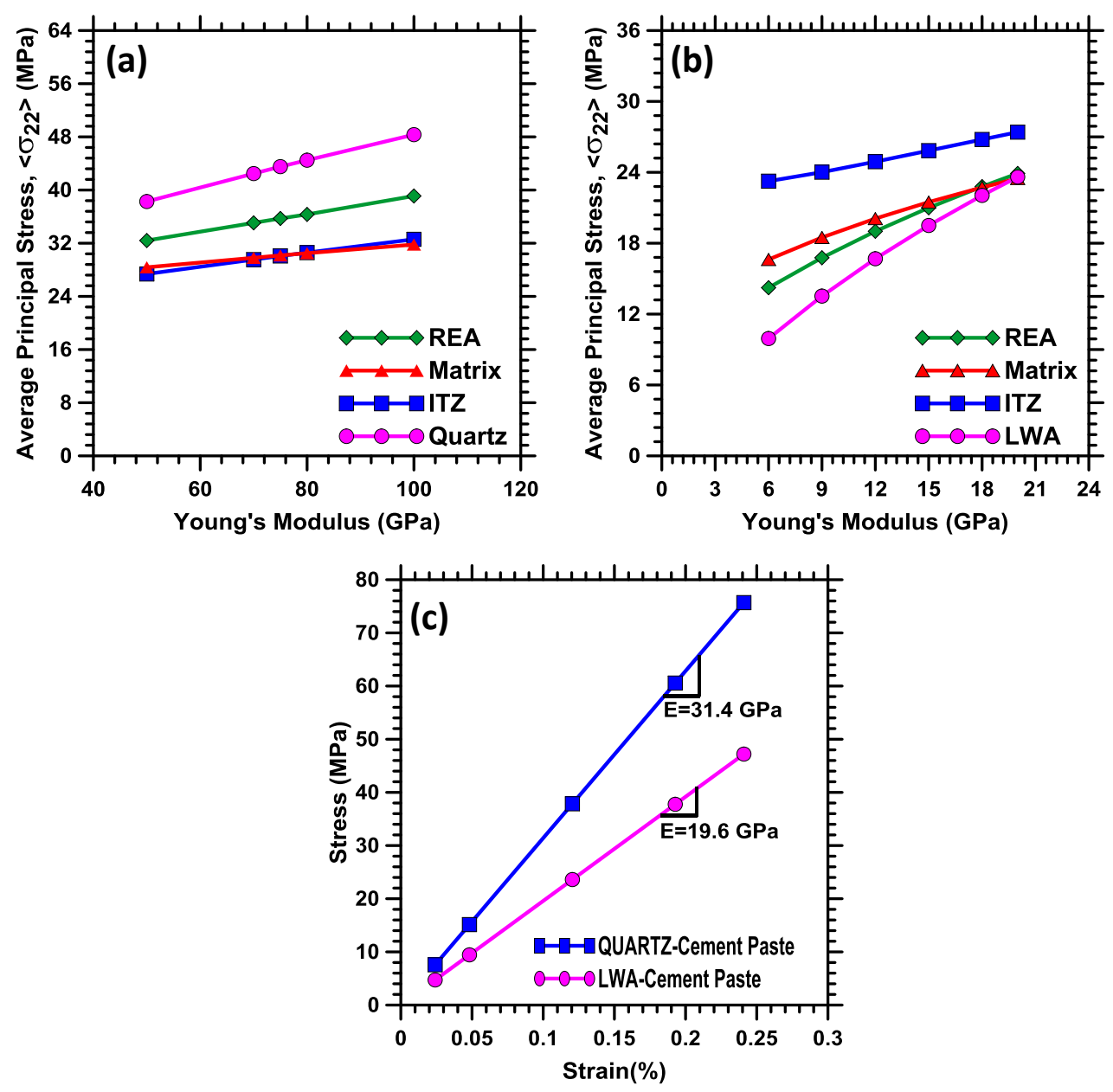

Figure 9: Effective REA and individual component stresses $\left(\sigma_{22}\right)$ as a function of inclusion stiffness for:

(a) quartz mortar system and (b) LWA mortar system; and (c) linear constitutive relationship for quartz and LWA mortar systems for defaults values of material parameters (shown in Table 1) and microstructural features.

\subsubsection{Influence of matrix and ITZ stiffening}

This section reports the influence of matrix as well as ITZ strengthening/stiffening (such as those accomplished through the use of additives like silica fume as a partial replacement of cement) in mortars containing quartz or LWA as inclusions with an aim of understanding the relative influences of matrix modification. The Young's modulus of silica fume modified cement paste is taken as $25 \mathrm{GPa}$ [58] as opposed to $20 \mathrm{GPa}$ for the unmodified systems. The stiffness of the ITZ was also increased proportionally (Young's modulus of ITZ is taken as 18.75 and 37.5 GPa in quartz and LWA mortars 
respectively) since silica fume incorporation is known to result in interface densification and stiffening [58,59]. Figures 10 (a) and (b) show average stresses in the REA as well as in the individual microstructural phases corresponding to an applied strain of $0.12 \%$ for the quartz and LWA mortars respectively. Stresses increase in all the phases for both the mortar types when the paste phase contains silica fume. In the quartz mortar, the average stress in the ITZ increased by about $15 \%$ when $10 \%$ silica fume was incorporated. However, the strength enhancement of both the ITZ and the paste phase will likely be larger than the stress increase, thereby rendering improved mechanical performance to the quartz mortar when silica fume is incorporated in the paste phase. This has been demonstrated through experimental studies $[58,60]$. The stress increase inside the quartz inclusions has an insignificant influence on material failure because of the higher strength of quartz particles [61]. On the contrary, the inclusions in the LWA mortar system are relatively weak and even a marginal increase in inclusion stress is likely to result in material failure at even lower applied strains as compared to that in LWA mortar systems without silica fume incorporation. Thus the combined stiffening of ITZ as well as the matrix in LWA mortar system has a detrimental effect on the strength, provided it is the lightweight inclusion that is weaker and fails first. This points to the fact that matrix strengthening methods such as the use of silica fume might not be beneficial from a viewpoint of mechanical response in these systems, unless the LWA is stronger. However, the densification of the matrix and the ITZ will still lead to better durability properties in such concretes.
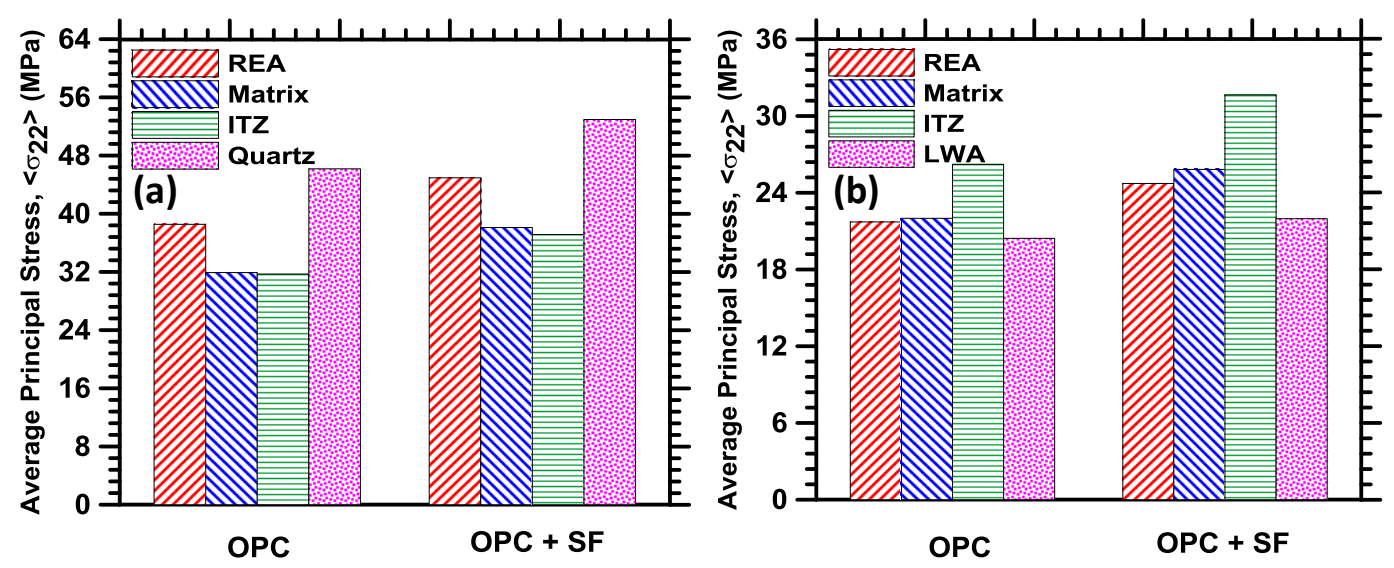

Figure 10: Effect of silica fume incorporation on the average REA and phase stresses for: (a) mortar containing quartz inclusion, and (b) mortar with LWA inclusions. The modified matrices contain $10 \%$ silica fume by mass as a cement replacement material.

\subsection{Influence of Inclusion Content}


The preceding sections have dealt with systems containing a constant inclusion volume fraction of $50 \%$. Figures $11(a)$ and (b) show the effect of inclusion volume fraction on the average principal stresses in the quartz and LWA mortars respectively. With increasing volume fraction of inclusions, the average REA stresses as well as the stresses in all the phases in both the systems increase linearly. For the quartz mortar (Figure 11(a)), the rates of stress increase in the microstructural phases as well as the REA as a function of the inclusion volume fraction are higher as compared to those in LWA mortar (Figure 11(b)). This is once again attributed to the higher stiffness of quartz inclusions. While an increase in the ITZ stress at higher volume fractions of quartz is likely to be responsible for interface failure (since ITZ is the weakest component in the quartz mortar) and thus the material failure under smaller applied strains in quartz mortar, a stress increase inside the LWA inclusions (which is the weakest component in the LWA mortar) at higher volume fractions of LWA is expected to be the cause of failure of LWA mortar system under smaller external applied strains.
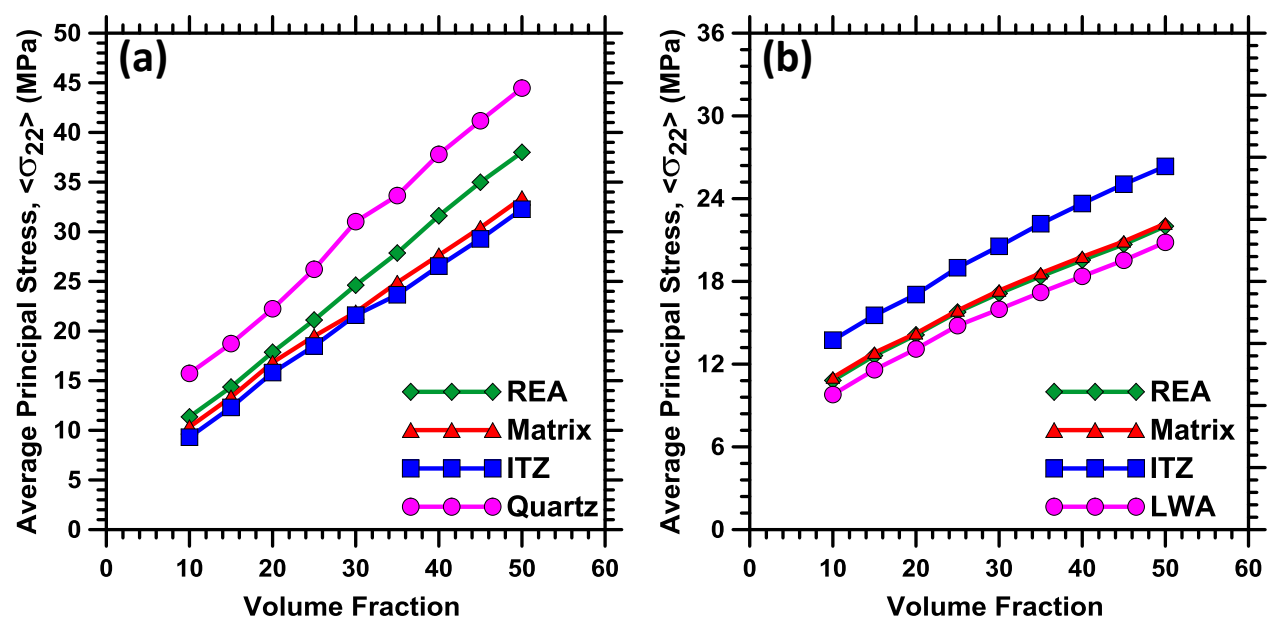

Figure 11: Effective REA and individual phase stresses as a function of inclusion volume fraction for: (a) quartz mortar and (b) LWA mortar.

\subsection{LWA Mortar with Multi-Sized Particles: Microstress Distribution and REA Stresses}

While all the previous parametric studies considered the response of systems with single sized inclusions, the influence of several inclusion sizes (as is the realistic case) on the average REA and phase stresses is dealt with in this section. Default values of material/geometrical properties of inclusions, paste, and ITZ (Table 1) are used here. Here the area fraction of ITZ is kept constant at $3.36 \%$ and the thickness of ITZ varies with the size of inclusions. Table 2 shows the three different uniform inclusion size distributions used in this study. The inclusion sizes are uniformly distributed around a mean of 0.6 
$\mathrm{mm}$ and standard deviations of $0.06,0.12$, and $0.24 \mathrm{~mm}$ respectively. Figures $12(\mathrm{a})$ and (b) show the dominant principal stress $\left(\sigma_{22}\right)$ distribution in single- and multi-sized particulate (LWA) systems respectively. Here, LWA inclusions with a mean size of $0.6 \mathrm{~mm}$ and a standard deviation of $0.24 \mathrm{~mm}$ are considered. Figures 12(a) and (b) also show enhanced stress concentrations between the closely spaced inclusions, especially if they are aligned in a direction perpendicular to that of the applied strain. In Figure 12(b), when smaller particles, particularly with varying sizes are in proximity with each other, a slight reduction in stress is observed. With smaller particles, there is a reduction in the continuous volume of ITZs (the highly stressed phases in the LWA mortar systems) that are adjacent to each other, resulting in such an observation. These are reflected in the individual phase stresses as well as the average principal REA stresses for the different particle size distributions, which are shown in Figures 13(a) and (b) respectively. These figures provide average stress information on mortars containing $50 \%$ LWA inclusions by volume. The averaged stresses are highest in the single-sized LWA mortar due to the higher stress concentrations in the inter-inclusion areas as explainer earlier. The stresses reduced considerably (by about 20\%) when non-uniform particle sizes are considered since interactions between neighboring smaller and larger particles reduce the stresses, contrary to the higher stressconcentrations encountered between two closely spaced similar-sized inclusions. For the same reason, the averaged REA stresses also decrease as the inclusion size distribution is more spread out (the mean size being the same), as reflected in Figures 13 (a) and (b). 


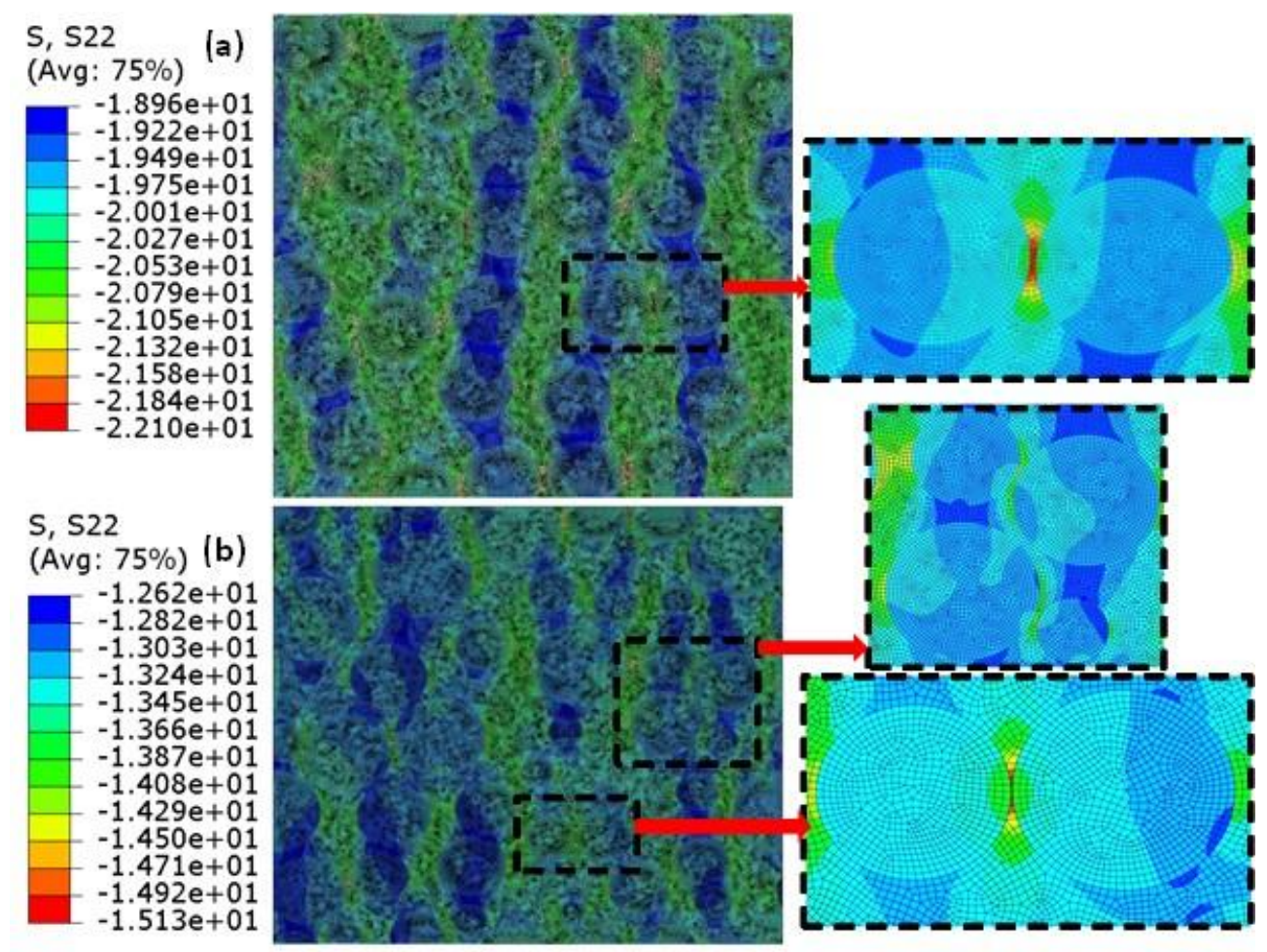

Figure 12: Influence of particle sizes on the dominant principal Stresses (MPa) in the REA for: (a) singlesized LWA inclusions, and (b) multiple sized (Mean $=0.6 \mathrm{~mm}$ and std. dev. $=0.24 \mathrm{~mm}$ ) LWA inclusions embedded in a cement paste. Magnified representation of stress distributions in the vicinity of the particles (similar and dissimilar sizes) are shown for clarity.

Table 2: Size distributions (uniform distribution) of the LWA particulate inclusions for FE simulation

\begin{tabular}{|l|c|c|c|}
\hline PSD Type & $\begin{array}{c}\text { Range } \\
(\mathrm{mm})\end{array}$ & $\begin{array}{c}\text { Mean } \\
(\mathrm{mm})\end{array}$ & $\begin{array}{c}\text { Std. Dev. } \\
(\mathrm{mm})\end{array}$ \\
\hline Single Size & NA & 0.6 & 0 \\
\hline Multiple Size (Narrow) & $0.5-0.7$ & 0.6 & 0.06 \\
\hline Multiple Size (Medium) & $0.4-0.8$ & 0.6 & 0.12 \\
\hline Multiple Size (Wide) & $0.2-1.0$ & 0.6 & 0.24 \\
\hline
\end{tabular}




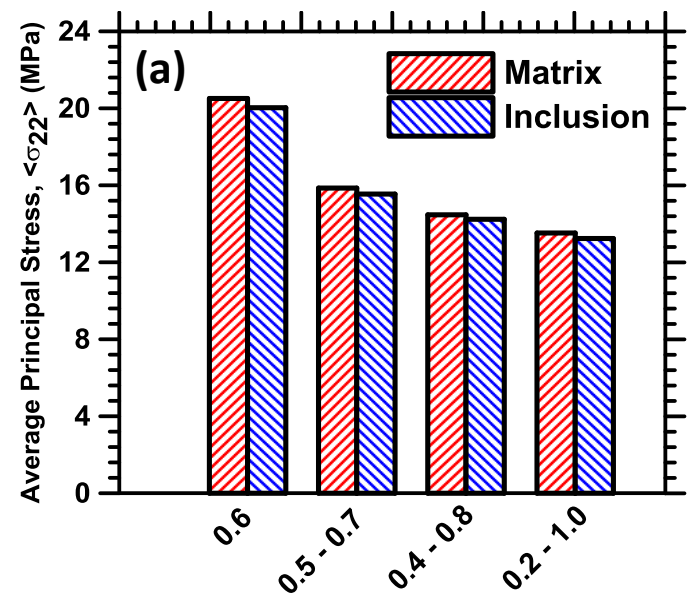

Particle size range $(\mathrm{mm})$

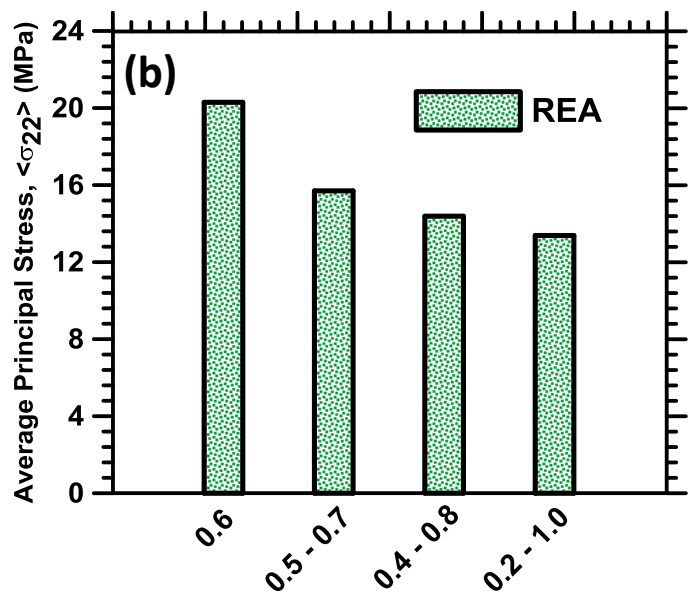

Particle size range $(\mathrm{mm})$

Figure 13: Effect of LWA inclusion size distribution on: (a) the matrix and inclusion stresses; and (b) effective REA stresses (mean particle size is $0.6 \mathrm{~mm}$ )

\subsection{Micromechanics-Based Elastic Modulus Predictions}

\subsubsection{Comparison with analytical modeling schemes}

Predicting the material properties of composite systems is an important attribute desired from a micromechanical model, so that material design decisions could be made in a rational manner with limited experiments. This section compares the composite Young's modulus values predicted using the above-described micromechanical model as well as using well-established analytical models such as Mori-Tanaka [62], double inclusion [63] and Hobbs method [64]. Mori-Tanaka (M-T) method has been previously used for determination of effective properties of cement-based materials [15,65-67]. It considers a discrete spherical inclusion embedded in an infinitely extended homogeneous reference medium (matrix). The homogenized elastic moduli for two-phase materials can be quantified from the individual phase properties as recently explained in [21,62]]. A two-step homogenization is performed for the determination of effective Young's modulus for binder systems using the M-T method. In Step I, the cement paste and ITZ are homogenized and in Step II, the inclusions and the resultant phase from Step-I (which is the new reference medium) are homogenized. While the Mori-Tanaka model consists of an ellipsoidal inclusion in an infinitely extended homogeneous reference medium, the double inclusion (DI) model considers an ellipsoidal inclusion embedded in another ellipsoidal matrix, which is further embedded in an infinitely extended homogeneous medium [18,63]. Detailed derivation and analysis procedure are described in $[18,63,66]$. Here the inclusion (quartz or LWA) is considered to be embedded in ITZ, and this composite particle is embedded in an infinite cement paste matrix. 
Another analytical homogenization approach derived by Hobbs [64] is also used here for comparison. The resultant homogenized Young's modulus ( $\left.E^{*}\right)$ for a two-phase composite is given as:

$$
E^{*}=E_{m}\left[1+\frac{2 \phi_{i}\left(E_{i}-E_{m}\right)}{\left(E_{i}+E_{m}\right)-\phi_{i}\left(E_{i}-E_{m}\right)}\right]
$$

where $\phi_{i}$ is the volume fraction of the inclusions, and $E_{\mathrm{i}}$ and $E_{\mathrm{m}}$ are the Young's modulus of the inclusion and matrix respectively. Here also, a two-step homogenization procedure for the multiple phases as adopted for the M-T method is carried out in order to obtain the homogenized Young's modulus.

It needs to be noted here that the analytical schemes such as Mori-Tanaka method are based on Eshelby's solution for a single ellipsoidal inclusion in an infinite field. On the other hand, the numerical simulations are performed on 2D microstructures with circular inclusions under plane strain condition, which does not directly correspond to the assumption of spherical/ellipsoidal inclusions used in analytical schemes. However, the comparison between numerical and analytical schemes presented here is intended towards exploring the relative efficiency of the two fundamentally different methods to predict the effective responses in such cementitious systems.

Figures 14(a) and (b) show the composite Young's modulus with varying inclusion volume fractions for quartz and LWA mortar systems respectively. The Young's modulus increases significantly in the quartz mortar with increasing volume fraction of inclusions whereas it decreases with increasing inclusion volume fraction in the LWA mortars, as expected. In both the systems, the M-T and double inclusion models predict higher values of Young's modulus as compared to those quantified using the micromechanical FE analysis. This is because these analytical schemes do not adequately capture the realistic inter-inclusion interactions that result in stress-concentrations/relaxations in these microheterogeneous systems that influence the composite REA stresses for a given imposed strain. Hobbs method is also a simple geometry-independent and volume-fraction based analytical method which also does not capture stress-concentrations in heterogeneous systems with complex geometries. On the contrary, a numerical scheme such as the one described here adequately captures such interactions [22]. Besides, the accuracy of the analytical homogenization techniques has been shown to be limited if the stiffness contrast between the phases is high [22,68]. This is reflected in Figures $14(\mathrm{a})$ and (b) that shows the predicted elastic modulus as a function of the inclusion volume fraction for both the quartz and LWA mortars. In the quartz mortar system $\left(E_{\text {inclusion }} / E_{\text {paste }}=3.5\right)$ with $50 \%$ inclusion volume fraction, the analytical schemes (M-T and DI) predict about $20 \%$ higher value of homogenized Young's modulus as compared to the micromechanical FE analysis. On the other hand, the homogenized Young's moduli predicted using analytical schemes are about $10 \%$ higher than that quantified using the FE analysis for 
the LWA mortar system $\left(E_{\text {inclusion }} / E_{\text {paste }}=0.8\right)$. In the case of quartz mortar, the Young's modulus predicted by Hobbs method correlates well with that obtained using numerical simulation at lower quartz volume fractions (up to $30 \%$ ). However, the predictions diverge at higher quartz volume fractions because of the dilute limit being exceeded and the inter-particle interactions becoming dominant, the effect of which cannot be accounted for by analytical models. The trends in Figure 14 suggest that Hobbs method over-predicts the Young's modulus as compared to numerical approach when the inclusions are stiffer than the matrix and under-predicts it when the inclusions are softer than the matrix. A comparison of the results from the numerical analysis scheme to the experimentally determined elastic moduli is shown in the forthcoming section.
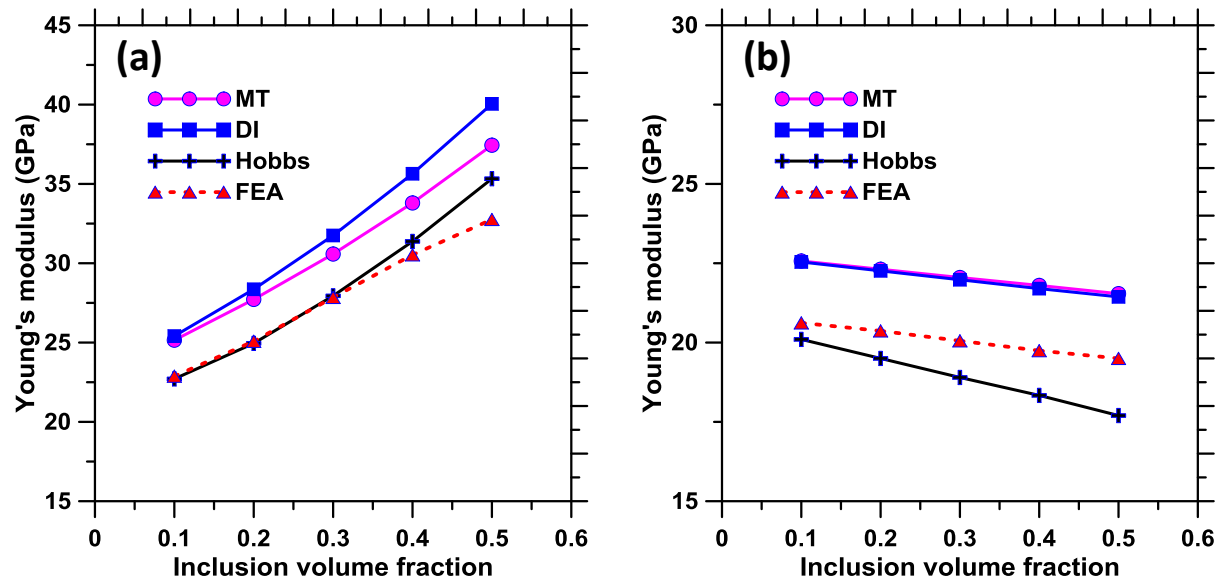

Figure 14: Young's modulus predicted using the micromechanical model and its comparison with wellestablished analytical models for: (a) quartz mortar and (b) LWA mortar

\subsubsection{Experimental validation}

To validate the micromechanical FE model, experimental values of Young's modulus of quartz mortar at different volume fractions of quartz has been adopted from an experimental study [54] where the elastic modulus was measured in accordance with ASTM C469, using cylindrical specimens (10 cm diameter $\times 20 \mathrm{~cm}$ height). For numerical simulations, the Young's modulus of quartz, cement paste and ITZ were taken as $64 \mathrm{GPa}, 16.75 \mathrm{GPa}$ and $8.375 \mathrm{GPa}$ respectively, ITZ thickness as $5 \mu \mathrm{m}$, and the Poisson's ratio of all the components as 0.22 as reported in the above-referenced experimental study. Four different volume fractions of quartz $(10,20,30$ and $55 \%)$ are used for simulations. For the numerical analysis, four replicate microstructures with random spatial distributions were generated for each of the inclusion volume fractions. The median inclusion size of quartz for the micromechanical analysis was matched to those used in the experimental studies (365 $\mu \mathrm{m})$. Figure 15 shows the Young's 
modulus of quartz mortar, predicted using the FE scheme (principal stresses and strains measured in the REA, when the microstructure was subjected to different strains in the linear elastic regime, as shown in section 3.1.1) along with the experimental measurements. A very good correlation is noticed between the predicted and measured Young's modulus as can be seen from this figure, contrary to the analytical schemes, establishing the viability of using the numerical homogenization scheme in determining the Young's modulus of micro-heterogeneous systems. Also, the standard deviations of the predicted Young's modulus values from four replicate microstructures are negligible as compared to standard deviations of experimental measurements, reinforcing the efficacy of using microstructure-guided numerical simulation towards prediction of Young's modulus.

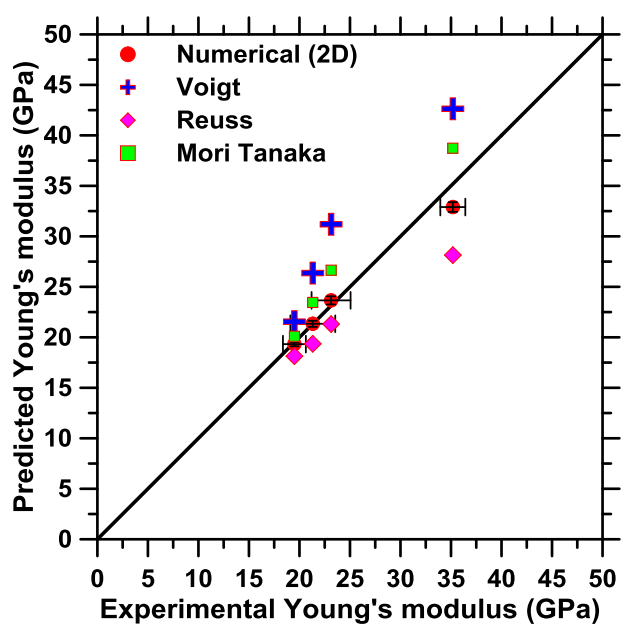

Figure 15: Relationship between experimentally obtained $\mathrm{E}$ value and those predicted using the micromechanical FE scheme and analytical techniques for a mortar containing different volume fractions of quartz particles.

\section{CONCLUSIONS}

This paper was motivated by the desire to fundamentally understand the modifications in the microstructural stress distributions as a function of the stiffness of the inclusions, so as to enable microstructure-guided design of sustainable or special-performance cementitious particulate composite systems. This study has investigated the influence of individual phase properties on the stresses in the microstructural components as well as the REA of quartz and LWA mortars when subjected to varying displacements in the linear elastic regime. A microstructure-based strain-controlled virtual testing scheme was employed. The virtual microstructures were generated using a particle-packing-based algorithm. The choice of a periodic microstructure with periodic boundary conditions has been 
elucidated in detail and microstructural stress analysis was performed using the finite element method. Microstructural stress distributions and averaged REA stress as well as individual component stresses were evaluated for various material- and geometry-related parameters in quartz and LWA mortars.

Numerical simulations revealed stress concentrations inside the harder inclusion phase in the quartz mortar whereas the LWA mortar exhibited stress concentration at the ITZ. While the failure of traditional quartz mortar system is not dictated by stress inside quartz particles due to their higher strength, the stress inside weaker LWA inclusions in such mortars becomes critical due to the lower strength of LWA inclusions. Since increasing the strength and stiffness of LWA inclusions also results in increase in stress in the LWA inclusions, a balance need to be sought between the strength of LWA inclusions and the resultant stress enhancement. Such an issue is non-existent for mortars containing hard inclusions such as quartz. Combined stiffening of matrix as well as ITZ with techniques such as silica fume incorporation yielded increase in stresses in all the components in both the systems. Increase in the ITZ stress (weakest component in quartz mortar system) could be counteracted by strength enhancement of ITZ and thus superior performance obtained through silica fume incorporation in conventional quartz mortars. But, same was not found true for the LWA mortar since the stress in the LWA inclusions increases with increasing ITZ and matrix stiffness while the strength of LWA remains unaltered. Hence traditional strengthening and stiffening of matrix as well as ITZ is not a viable technique of performance enhancement in LWA mortar.

The microstructure-based numerical technique accurately captured the stress concentrations in these systems. This resulted in improved predictions of the elastic modulus using the micromechanical scheme, especially for the systems where stiffness contrast between the phases is high, as compared to many analytical homogenization schemes. This study thus links the microstructure with mechanical behavior of two different micro-heterogeneous materials to bring out their fundamental difference in micro-stress distribution and provides valuable input towards material design of such non-traditional cementitious systems with different inclusions of varying stiffness.

\section{ACKNOWLEDGEMENTS}

The authors gratefully acknowledge partial supports from the National Science Foundation (CMMI: 1130028 and 1463646) and an Infravation ERA-NET Plus grant (31109806.0001) at Arizona State University (ASU) towards this study. SD acknowledges the support from COE and CVE department at the University of Rhode Island (URI). The contents of this paper reflect the views of the authors who are

responsible for the facts and accuracy of the data presented herein, and do not necessarily reflect the 
views and policies of the funding agency, nor do the contents constitute a standard, specification, or a regulation.

\section{REFERENCES}

[1] K.S. Al-Jabri, A.W. Hago, A.S. Al-Nuaimi, A.H. Al-Saidy, Concrete blocks for thermal insulation in hot climate, Cem. Concr. Res. 35 (2005) 1472-1479.

[2] D. Cusson, T. Hoogeveen, Internal curing of high-performance concrete with pre-soaked fine lightweight aggregate for prevention of autogenous shrinkage cracking, Cem. Concr. Res. 38 (2008) 757-765.

[3] H.K. Kim, J.H. Jeon, H.K. Lee, Workability, and mechanical, acoustic and thermal properties of lightweight aggregate concrete with a high volume of entrained air, Constr. Build. Mater. 29 (2012) 193-200.

[4] L.H. Nguyen, A.-L. Beaucour, S. Ortola, A. Noumowé, Influence of the volume fraction and the nature of fine lightweight aggregates on the thermal and mechanical properties of structural concrete, Constr. Build. Mater. 51 (2014) 121-132.

[5] F. Fernandes, S. Manari, M. Aguayo, K. Santos, T. Oey, Z. Wei, G. Falzone, N. Neithalath, G. Sant, On the feasibility of using phase change materials (PCMs) to mitigate thermal cracking in cementitious materials, Cem. Concr. Compos. 51 (2014) 14-26.

[6] L. Hembade, N. Neithalath, S.D. Rajan, Understanding the energy implications of phase-change materials in concrete walls through finite-element analysis, J. Energy Eng. 140 (2013) 4013009.

[7] A.M. Thiele, A. Jamet, G. Sant, L. Pilon, Annual energy analysis of concrete containing phase change materials for building envelopes, Energy Convers. Manag. 103 (2015) 374-386.

[8] F. Hernández-Olivares, G. Barluenga, M. Bollati, B. Witoszek, Static and dynamic behaviour of recycled tyre rubber-filled concrete, Cem. Concr. Res. 32 (2002) 1587-1596.

[9] I. Akkurt, C. Basyigit, S. Kilincarslan, B. Mavi, A. Akkurt, Radiation shielding of concretes containing different aggregates, Cem. Concr. Compos. 28 (2006) 153-157.

[10] A.S. Makarious, I.I. Bashter, A. El-Sayed Abdo, M. Samir Abdel Azim, W.A. Kansouh, On the utilization of heavy concrete for radiation shielding, Ann. Nucl. Energy. 23 (1996) 195-206.

[11] J.A. Bogas, A. Gomes, Compressive behavior and failure modes of structural lightweight aggregate concrete - Characterization and strength prediction, Mater. Des. 46 (2013) 832-841.

[12] C.R. Cheeseman, G.S. Virdi, Properties and microstructure of lightweight aggregate produced from sintered sewage sludge ash, Resour. Conserv. Recycl. 45 (2005) 18-30.

[13] J.M. Chi, R. Huang, C.C. Yang, J.J. Chang, Effect of aggregate properties on the strength and stiffness of lightweight concrete, Cem. Concr. Compos. 25 (2003) 197-205.

[14] A.U. Nilsen, P.J.M. Monteiro, O.E. Gjørv, Estimation of the elastic moduli of lightweight aggregate, Cem. Concr. Res. 25 (1995) 276-280.

[15] C.C. Yang, Approximate Elastic Moduli of Lightweight Aggregate, Cem. Concr. Res. 27 (1997) 10211030.

[16] C.-C. Yang, R. Huang, Approximate Strength of Lightweight Aggregate Using Micromechanics Method, Adv. Cem. Based Mater. 7 (1998) 133-138.

[17] E. Stora, Q.-C. He, B. Bary, Influence of inclusion shapes on the effective linear elastic properties of hardened cement pastes, Cem. Concr. Res. 36 (2006) 1330-1344.

[18] C.C. Yang, R. Huang, Double inclusion model for approximate elastic moduli of concrete material, Cem. Concr. Res. 26 (1996) 83-91. 
[19] Y. Ke, S. Ortola, A.L. Beaucour, H. Dumontet, Identification of microstructural characteristics in lightweight aggregate concretes by micromechanical modelling including the interfacial transition zone (ITZ), Cem. Concr. Res. 40 (2010) 1590-1600.

[20] R. Zouari, A. Benhamida, H. Dumontet, A micromechanical iterative approach for the behavior of polydispersed composites, Int. J. Solids Struct. 45 (2008) 3139-3152.

[21] S. Das, P. Yang, S.S. Singh, J.C.E. Mertens, X. Xiao, N. Chawla, N. Neithalath, Effective properties of a fly ash geopolymer: Synergistic application of X-ray synchrotron tomography, nanoindentation, and homogenization models, Cem. Concr. Res. 78 (2015) 252-262.

[22] C.F. Dunant, B. Bary, A.B. Giorla, C. Péniguel, J. Sanahuja, C. Toulemonde, A.-B. Tran, F. Willot, J. Yvonnet, A critical comparison of several numerical methods for computing effective properties of highly heterogeneous materials, Adv. Eng. Softw. 58 (2013) 1-12.

[23] Z.M. Wang, A.K.H. Kwan, H.C. Chan, Mesoscopic study of concrete I: generation of random aggregate structure and finite element mesh, Comput. Struct. 70 (1999) 533-544.

[24] J. Saliba, F. Grondin, M. Matallah, A. Loukili, H. Boussa, Relevance of a mesoscopic modeling for the coupling between creep and damage in concrete, Mech. Time-Depend. Mater. 17 (2012) 481499.

[25] C.F. Dunant, K.L. Scrivener, Micro-mechanical modelling of alkali-silica-reaction-induced degradation using the AMIE framework, Cem. Concr. Res. 40 (2010) 517-525.

[26] P. Grassl, M. Jirásek, Meso-scale approach to modelling the fracture process zone of concrete subjected to uniaxial tension, Int. J. Solids Struct. 47 (2010) 957-968.

[27] P. Havlásek, M. Jirásek, Multiscale modeling of drying shrinkage and creep of concrete, Cem. Concr. Res. 85 (2016) 55-74.

[28] S. Das, A. Maroli, S.S. Singh, T. Stannard, X. Xiao, N. Chawla, N. Neithalath, A microstructure-guided constitutive modeling approach for random heterogeneous materials: Application to structural binders, Comput. Mater. Sci. 119 (2016) 52-64.

[29] F. Lavergne, K. Sab, J. Sanahuja, M. Bornert, C. Toulemonde, Investigation of the effect of aggregates' morphology on concrete creep properties by numerical simulations, Cem. Concr. Res. 71 (2015) 14-28.

[30] J. Escoda, F. Willot, D. Jeulin, J. Sanahuja, C. Toulemonde, Estimation of local stresses and elastic properties of a mortar sample by FFT computation of fields on a 3D image, Cem. Concr. Res. 41 (2011) 542-556.

[31] Y. Ke, S. Ortola, A.L. Beaucour, H. Dumontet, Micro-stress analysis and identification of lightweight aggregate's failure strength by micromechanical modeling, Mech. Mater. 68 (2014) 176-192.

[32] E. Malachanne, R. Sassine, E. Garcia-Diaz, F. Dubois, Numerical model for mechanical behavior of lightweight concrete and for the prediction of local stress concentration, Constr. Build. Mater. 59 (2014) 180-187.

[33] S. Li, Boundary conditions for unit cells from periodic microstructures and their implications, Compos. Sci. Technol. 68 (2008) 1962-1974.

[34] O. van der Sluis, P.J.G. Schreurs, W.A.M. Brekelmans, H.E.H. Meijer, Overall behaviour of heterogeneous elastoviscoplastic materials: effect of microstructural modelling, Mech. Mater. 32 (2000) 449-462.

[35] Z. Xia, C. Zhou, Q. Yong, X. Wang, On selection of repeated unit cell model and application of unified periodic boundary conditions in micro-mechanical analysis of composites, Int. J. Solids Struct. 43 (2006) 266-278.

[36] F. Grondin, M. Matallah, How to consider the Interfacial Transition Zones in the finite element modelling of concrete?, Cem. Concr. Res. 58 (2014) 67-75.

[37] Z. Hashin, P.J.M. Monteiro, An inverse method to determine the elastic properties of the interphase between the aggregate and the cement paste, Cem. Concr. Res. 32 (2002) 1291-1300. 
[38] Y. Ke, A.L. Beaucour, S. Ortola, H. Dumontet, R. Cabrillac, Influence of volume fraction and characteristics of lightweight aggregates on the mechanical properties of concrete, Constr. Build. Mater. 23 (2009) 2821-2828.

[39] M.P. Lutz, P.J.M. Monteiro, R.W. Zimmerman, Inhomogeneous Interfacial Transition Zone Model for the Bulk Modulus of Mortar, Cem. Concr. Res. 27 (1997) 1113-1122.

[40] C.C. Yang, Effect of the Transition Zone on the Elastic Moduli of Mortar, Cem. Concr. Res. 28 (1998) 727-736.

[41] V. Zanjani Zadeh, C.P. Bobko, Nanomechanical characteristics of lightweight aggregate concrete containing supplementary cementitious materials exposed to elevated temperature, Constr. Build. Mater. 51 (2014) 198-206.

[42] A. Peled, J. Castro, J. Weiss, Atomic Force Microscopy Examinations of Mortar Made by Using Water-Filled Lightweight Aggregate, Transp. Res. Rec. J. Transp. Res. Board. 2141 (2010) 92-101.

[43] F.A. Gilabert, D. Garoz, W. Van Paepegem, Stress concentrations and bonding strength in encapsulation-based self-healing materials, Mater. Des. 67 (2015) 28-41.

[44] S.-P. Lee, J.-W. Jin, K.-W. Kang, Probabilistic analysis for mechanical properties of glass/epoxy composites using homogenization method and Monte Carlo simulation, Renew. Energy. 65 (2014) 219-226.

[45] A. Drago, M.-J. Pindera, Micro-macromechanical analysis of heterogeneous materials: Macroscopically homogeneous vs periodic microstructures, Compos. Sci. Technol. 67 (2007) 12431263.

[46] M. Jiang, I. Jasiuk, M. Ostoja-Starzewski, Apparent elastic and elastoplastic behavior of periodic composites, Int. J. Solids Struct. 39 (2002) 199-212.

[47] M. Ainsworth, Essential boundary conditions and multi-point constraints in finite element analysis, Comput. Methods Appl. Mech. Eng. 190 (2001) 6323-6339.

[48] A. Kumar, T. Oey, S. Kim, D. Thomas, S. Badran, J. Li, F. Fernandes, N. Neithalath, G. Sant, Simple methods to estimate the influence of limestone fillers on reaction and property evolution in cementitious materials, Cem. Concr. Compos. 42 (2013) 20-29.

[49] H.A. Meier, E. Kuhl, P. Steinmann, A note on the generation of periodic granular microstructures based on grain size distributions, Int. J. Numer. Anal. Methods Geomech. 32 (2008) 509.

[50] S. Torquato, Random heterogeneous materials: microstructure and macroscopic properties, Springer Science \& Business Media, 2013.

[51] G. Van Rossum, others, Python Programming Language., in: USENIX Annu. Tech. Conf., 2007.

[52] P. Suquet, Elements of homogenization for inelastic solid mechanics, (1987).

[53] C.T. Sun, R.S. Vaidya, Prediction of composite properties from a representative volume element, Compos. Sci. Technol. 56 (1996) 171-179.

[54] G. Falzone, G.P. Falla, Z. Wei, M. Zhao, A. Kumar, M. Bauchy, N. Neithalath, L. Pilon, G. Sant, The influences of soft and stiff inclusions on the mechanical properties of cementitious composites, Cem. Concr. Compos. 71 (2016) 153-165.

[55] D.P. Bentz, K.A. Snyder, Protected paste volume in concrete: Extension to internal curing using saturated lightweight fine aggregate, Cem. Concr. Res. 29 (1999) 1863-1867.

[56] O. Kayali, Fly ash lightweight aggregates in high performance concrete, Constr. Build. Mater. 22 (2008) 2393-2399.

[57] R. Wasserman, A. Bentur, Effect of lightweight fly ash aggregate microstructure on the strength of concretes, Cem. Concr. Res. 27 (1997) 525-537.

[58] C. Hu, Z. Li, Property investigation of individual phases in cementitious composites containing silica fume and fly ash, Cem. Concr. Compos. 57 (2015) 17-26. 
[59] P. Duan, Z. Shui, W. Chen, C. Shen, Effects of metakaolin, silica fume and slag on pore structure, interfacial transition zone and compressive strength of concrete, Constr. Build. Mater. 44 (2013) 16.

[60] M.J. Shannag, High strength concrete containing natural pozzolan and silica fume, Cem. Concr. Compos. 22 (2000) 399-406.

[61] J.W. Axelson, E.L. Piret, Crushing of Single Particles of Crystalline Quartz - Application of Slow Compression, Ind. Eng. Chem. 42 (1950) 665-670.

[62] T. Mori, K. Tanaka, Average stress in matrix and average elastic energy of materials with misfitting inclusions, Acta Metall. 21 (1973) 571-574.

[63] M. Hori, S. Nemat-Nasser, Double-inclusion model and overall moduli of multi-phase composites, Mech. Mater. 14 (1993) 189-206.

[64] D.W. Hobbs, The dependence of the bulk modulus, Young's modulus, creep, shrinkage and thermal expansion of concrete upon aggregate volume concentration, Matér. Constr. 4 (1971) 107-114.

[65] W.R.L. da Silva, J. Němeček, P. Štemberk, Application of multiscale elastic homogenization based on nanoindentation for high performance concrete, Adv. Eng. Softw. 62-63 (2013) 109-118.

[66] G.K. Hu, G.J. Weng, The connections between the double-inclusion model and the Ponte Castaneda-Willis, Mori-Tanaka, and Kuster-Toksoz models, Mech. Mater. 32 (2000) 495-503.

[67] K. Miled, K. Sab, R. Le Roy, Effective elastic properties of porous materials: Homogenization schemes vs experimental data, Mech. Res. Commun. 38 (2011) 131-135.

[68] M.I. Idiart, F. Willot, Y.-P. Pellegrini, P. Ponte Castañeda, Infinite-contrast periodic composites with strongly nonlinear behavior: Effective-medium theory versus full-field simulations, Int. J. Solids Struct. 46 (2009) 3365-3382. 